The Effect of Estradiol$17 \beta$, Goitrogen(T3), and Flutamide on Gene Expression in Medaka, Oryzias latipes

J.E. Haut

September 6, 2005 
This document was prepared as an account of work sponsored by an agency of the United States Government. Neither the United States Government nor the University of California nor any of their employees, makes any warranty, express or implied, or assumes any legal liability or responsibility for the accuracy, completeness, or usefulness of any information, apparatus, product, or process disclosed, or represents that its use would not infringe privately owned rights. Reference herein to any specific commercial product, process, or service by trade name, trademark, manufacturer, or otherwise, does not necessarily constitute or imply its endorsement, recommendation, or favoring by the United States Government or the University of California. The views and opinions of authors expressed herein do not necessarily state or reflect those of the United States Government or the University of California, and shall not be used for advertising or product endorsement purposes.

This work was performed under the auspices of the U.S. Department of Energy by University of California, Lawrence Livermore National Laboratory under Contract W-7405-Eng-48. 


\title{
The Effect of Estradiol-17ß, Goitrogen (T3), and Flutamide on Gene Expression in Medaka, Oryzias latipes
}

\author{
Paper \\ by \\ Jennifer E. Haut
}

\begin{abstract}
Biotechnology Research Academy, Level IV
Edward Teller Education Center
\end{abstract}

Merrill F. West High School

Tracy, CA 95376

\author{
Hosted \\ by \\ Biosciences Directorate \\ Lawrence Livermore National Laboratory \\ Livermore, CA 94550
}




\section{Table of Contents}

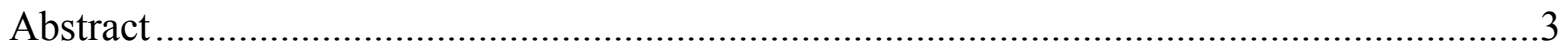

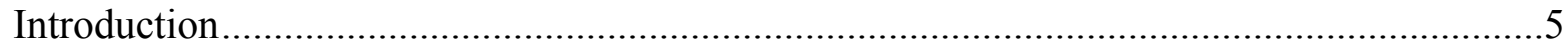

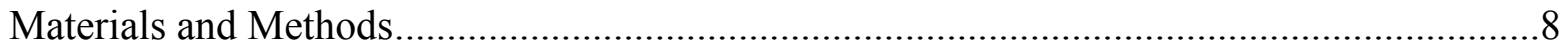

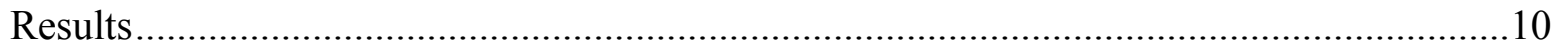

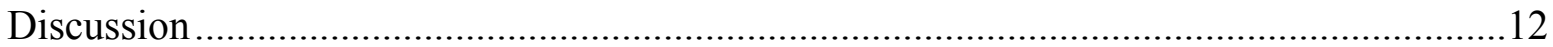

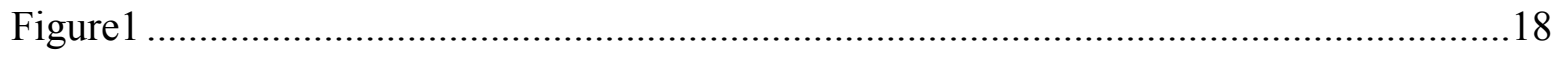

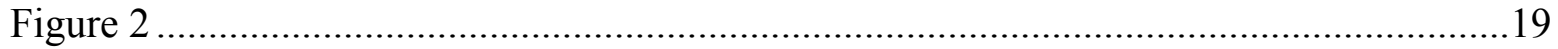

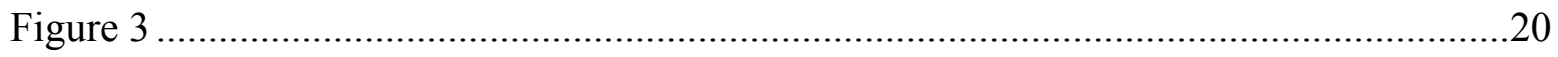

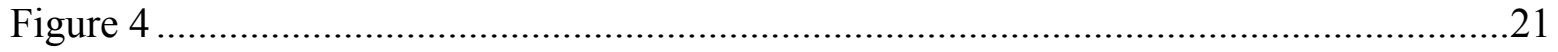

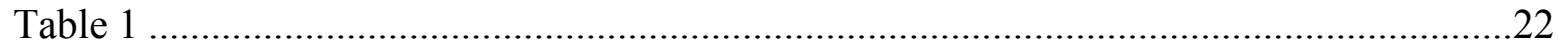

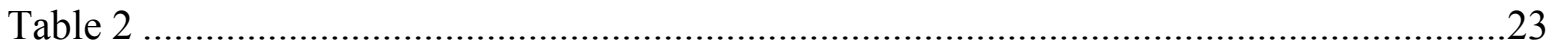

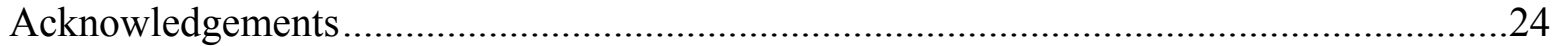

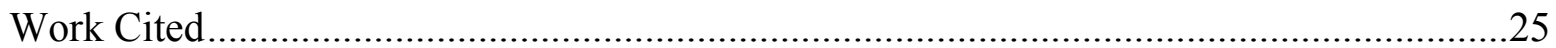




\begin{abstract}
Concern has been generated over the discovery of endocrine disrupting chemicals in rivers near sewage outflows. The presence of endocrine disrupting chemicals such as estradiol$17 \beta$ has been associated with a reduction of reproductive success in fish and an increase in the female phenotype and gonadal intersex in fish downstream of sewage treatment facilities. Such effects are believed to result from a disruption in the normal estrogenic pathways since estrogen plays a vital role in reproduction, sexual differentiation, the developments of secondary sex characteristics, and ovulation. Most studies have focused on the effect of a single endocrine disruptor on a single gene which does not provide for the interaction between genes. Microarray technology has made it possible to put an entire genome on a single chip so that researchers can get a clearer picture of the interaction of genes expressed in a cell and changes of said interactions when those cells are exposed to various conditions. Medaka males were exposed to known endocrine disruptors, estradial-17 $\beta$ and goitrogen, and medaka females were exposed to flutamide. All treatments were then compared to controls. Total RNA was extracted from the livers of both treated and untreated males and hybridized to a microarray chip designed to have EST sequences specific to medaka. ESTs were identified through two-channel microarray analysis and compared to GenBank using blastn searches to identify up regulated genes. Choriogenins $\mathrm{H}$ and $\mathrm{L}$, zona radiata, and vitellogenin, previously shown to be estrogen-induced in male fish were identified. Heat shock proteins (hsp70, hsp90, and hsp8) were also induced by estradiol-17 $\beta$, as was choriogenin Hminor. Exposure to goitrogen (T3) resulted in the induced expression of glutathione S-transferase and a GABA receptor protein in male medaka. Treatment with flutamide, an antiandrogen, caused the up regulation of choriogenin L, choriogenin Hminor, and zona radiata-2 in female medaka.
\end{abstract}


Further study of the genes identified in this study may serve as possible biomarkers to signal the effects caused by the presence of endocrine disruptors and provide a screening mechanism for the presence of estrogens in the environment. Microarray technology may provide a means to screen multiple biomarkers simultaneously and provide a more rapid and accurate tool for assessing endocrine disruption due to environmental pollutants. 


\section{Introduction}

Since the 1970s, Medaka has served as a useful model for studying various fields of environmental science, including radiation biology, carcinogenesis, and toxicology [1]. Medaka has gained popularity as a model for testing the effects of environmental chemicals, in particular, endocrine-disrupting chemicals and their effects on reproduction.

Medaka, Oryzias latipes, is a small, egg-laying freshwater fish native to Asia [2]. As a laboratory animal, medaka is an easy species to maintain because it is very hardy and less susceptible to common fish diseases. This fish species is ideal for vertebrate developmental studies for a number of reasons. The male and female medaka fish are easily distinguished by their external morphology [3], fig. 1. The species is highly prolific, producing $30-50$ eggs daily and up to 3,000 eggs during mating season [2]. They have a short generation time, 6-8 weeks, and early development is rapid. Eggs hatch 7 days after fertilization and the new frey become sexually mature in 3 months [3]. Medaka has also proven to be a useful model in genetic studies. It has a relatively small genome of $800 \mathrm{Mb}$ contained within 48 chromosomes [3]. Like mammals, sex determination in the medaka is based on the XY system. This fish was the first vertebrate used to demonstrate Mendelian inheritance and the first animal to undergo reverse sex differentiation in both directions in response to the exposure of exogenous sex hormones during the larval stage of development [3].

Endocrine disrupting chemicals can interfere with the normal function of the endocrine system in a variety of mechanisms [5]. Such chemicals can mimic sex steroid hormones and bind to natural receptor sites in the cell, either agonistically or antagonistically. They may interfere with normal endocrine function by modifying the production and breakdown of natural hormones or the hormone receptors within the body. Endocrine disruptors include both natural 
and synthetic compounds. They can be found in the environment, food products, plants (natural hormones), household products (breakdown products of detergents), pharmaceuticals (such as the estrogens found in birth control pills), etc.

It has become well established that a number of these endocrine disrupting chemicals are being discharged into the environment through agricultural run-off, incineration, and industrial and municipal effluents. Environmental exposure to various endocrine disrupting chemicals have been associated with abnormal thyroid function in birds and fish; decreased fertility in birds, fish, and mammals; decreased number of eggs laid and hatched by fish and birds; feminization of male fish; masculinization of female fish; and the alteration of immune response in birds and mammals $[6,7,8,9]$. Most of the evidence for endocrine disruption in wildlife comes from studies of species living in aquatic environments where, it turns out, much of these endocrine disrupting chemicals are being dumped [10].

Most studies have focused on the effect of a single endocrine disruptor on a single gene. This method, however, does not provide for the interaction of other genes on the particular gene of interest. The fact that numerous genes and their products function in specific and complicated patterns within a living organism is not easily discerned with single gene studies. Microarray technology has made it possible to put an entire genome on a single chip so that researchers can get a clearer picture of the interaction of genes expressed in a cell and changes of said interactions when those cells are exposed to various conditions [11]. An experiment on a single DNA chip can generate data on thousands of genes simultaneously. Such data can be used to identify gene sequences and possible mutations and determine gene expression levels. Researchers in the field of toxicology are now turning to this high-throughput method of studying genomics to find correlations between toxic responses to toxicants and possible changes 
in the genetic profiles of organisms exposed to those toxicants. This has generated a new field of study called toxicogenomics, the cross between functional genomics and molecular toxicology [11].

The purpose of this study is to identify, from microarray data, the specific genes in medaka which have higher expression levels as a result of exposure to 3 different endocrine disruptors, estradiol-17 $\beta$, goitrogen (T3), and flutamide. Preliminary analysis of gene expression data conducted by a colleague at Lawrence Livermore National Laboratories (LLNL) revealed that there were 378, 277 and 768 genes up regulated under the influence of estradiol-17ß, goitrogen (T3), and flutamide respectively. This data included a list of the accession numbers of Expressed Sequence Tags (ESTs) that represented the probes on the gene chip that were differentially expressed. Analysis on these ESTs was work done in this present study. The NCBI Blast program was used to find similarities between the series of ESTs identified from microarray analysis and sequences available in the NCBI (National Center for Biotechnology Information) GenBank database.

The goal of this project and related studies is to learn and understand the details and complexities of the specific genetic expression and regulation involved in the exposure to endocrine disruptors such as estradiol-17 , goitrogen (T3), and flutamide using microarray technology. Because such chemicals have demonstrated effects on wildlife, there is a concern for human health and safety. Although the role of endocrine disruptors in human disease has not been resolved, some studies correlate the environmental exposure to synthetic estrogenic chemicals with a decrease in sperm counts [12] and a decrease in male reproductive capacity [13]. Microarray data may offer more insight into the specific gene expression patterns caused by endocrine disrupting chemicals and provide a clearer picture of certain gene interactions. 
This may then lead to the development of better testing assays which would be useful in measuring and monitoring the amounts of endocrine disruptors such as estrogenic chemicals being released within the effluent of sewage and water-waste treatment facilities into the environment. Further research may also lead to the development of filtering mechanisms that could be applied to such facilities to reduce or remove the endocrine disruptors from the discharged effluent. 


\section{Materials and Methods}

Three different treatments were performed on medaka fish: 1) medaka males were exposed for 6 hours to prototypic estrogen (estradiol-17ß), $10 \mathrm{ppb}, 2$ ) medaka males were exposed for 6 hours to prototypic goitrogen (T3), $500 \mathrm{ppb}$, and 3) medaka females were exposed for 6 hours to prototypic antiandrogen (flutamide), $1 \mathrm{ppm}$. These treatments were compared to control medaka fish.

Total RNA was extracted from the livers of both treated and untreated medaka and then treated against DNA contamination with Ambion's DNA-free kit.

EST sequences specific to medaka in the NR database in GenBank were pooled and probes were designed for these sequences. These probes were then attached to the microarray chip. Two-channel microarray analysis was used, fig. 2. In this method, two separate RNA samples are used, the "experimental" and the "control". Each RNA is labeled with a different fluorescent dye, one green and one red. The two samples are then mixed and hybridized at the same time to the microarray chip. The microarray is then exposed to a laser which excites the fluorescent dyes. The number of photons in the experimental dye's spectrum is compared to the number of photons in the control dye's spectrum and is usually expressed as a ratio of the two numbers [14]. This method allowed for gene expression to be detected and measured.

Analysis of this data identified specific EST sequences that were up regulated in response to each compound. Using NCBI on a computer workstation, a standard nucleotide-nucleotide BLAST (blastn) sequence alignment [15] was then conducted on each of the EST sequences that demonstrated a 2-fold difference in expression from the control. From each EST query, the top 5 hits or sequence matches with an e-value of $\geq 0.005$ were collected and corresponding genes were 
then identified. Comparisons between treatment groups were then made to determine if any of the up regulated ESTs were identified in more than one treatment.

A more in depth analysis was conducted for the esradiol-17 $\beta$ treatment. A batch sequence alignment was performed on the resulting top sequence matches of ESTs identified from this treatment that demonstrated a 2-fold difference from the control using a UNIX system to identify similarities among the query list of ESTs and account for any repetitive or overlapping sequences within the list. ESTs were then grouped together by sequence similarity and gene descriptions were analyzed to identify genes that were induced by estradiol- $17 \beta$. 


\section{Results}

\section{Effects of Estradiol-17及}

Blastn sequence alignments were performed on 62 of the 378 ESTs that were up regulated. These sequences demonstrated a 2-fold difference from the control. These alignments identified 25 different groups based on EST sequence similarity. Five of these groups showed homology to the choriogenin $\mathrm{H}$ gene and 4 of these 5 also showed homology to the choriogenin Hminor gene, table 1. Two of the four with homology to both choriogenin $\mathrm{H}$ and choriogenin Hminor also showed similarity to the gene for a zona radiata structural protein. Four of the 25 groups showed homology for the gene, vitellogenin. Three unique ESTs were found to be homologous with the mRNA for heat shock protein 70 (hsp70). Two of the 25 groups showed homology with the mRNA for heat shock protein 90 (hsp90) and one of these was also homologous to the mRNA for heat shock protein 8 (hsp8). Two of the 25 groups showed homology with Tetradon nigroviridis (Freshwater Pufferfish) full-length cDNA. Four unique ESTs were homologous to Oryzias latipes cDNA clones. One unique EST was matched to a gene in Oryzias latipes for soluble guanylyl cyclase alpha unit. Another unique EST was matched to a zebrafish DNA sequence from a clone in linkage group 19. The final EST showed homology to a BAC clone in Homo sapiens.

\section{Effects of Goitrogen (T3)}

Fifteen of the 277 EST sequences demonstrated a 2-fold difference from the control. From the blastn sequence alignments of these sequences, 3 showed similarities with gstR1 mRNA for glutathione S-transferase, 1 showed similarity with a GABA receptor protein mRNA and 5 showed similarity with the Tetraodon nigroviridis full-length cDNA, table 1. 


\section{Effects of Flutamide}

Fifty-four of the 768 EST sequences showed a 2-fold difference when compared to the control. When compared with GenBank, 19 sequences aligned with the choriogenin L gene, table 1. Twelve EST sequences aligned with the choriogenin Hminor gene with one of these also showing similarity with zona radiata-2 mRNA. Five EST sequences showed similarity with the Tetraodon nigroviridis full-length cDNA.

\section{EST Comparison between Treatments}

There were a total of 876 different EST sequences identified by the 3 treatments, table 2 . Some ESTs were found to be up regulated in more than one treatment. Twenty-five ESTs were found to be induced in all treatments. Sixty were found to be induced by both flutamide and estradiol-17ß. Thirty ESTs were up regulated by both flutamide and goitrogen (T3) and 13 were up regulated by both estradiol-17 $\beta$ and goitrogen (T3). Fifty-six ESTs were uniquely up regulated as a result of goitrogen (T3) exposure. One hundred twenty-five up regulated ESTs were identified in only the estradiol-17 $\beta$ treatment. Six hundred fifty-two EST sequences were identified as being up regulated in only the flutamide treatment. 


\section{Discussion}

\section{Estradiol-17ß}

The induced up regulation of the gene for choriogenin $\mathrm{H}$ and choriogenin $\mathrm{L}$ seen in this study is consistent with results seen in previous studies using RT-PCR [16], dot blot anlaysis and in situ hybridization [17], and transgenic animal studies [18]. Choriogenins are proteins involved in the process of oogenesis in females.

The egg envelope in fish has two distinct layers. The outer layer is thin and forms around the oocytes and the inner layer, the zona radiata or eggshell, is thicker and makes up most of the egg envelope [19], fig. 3. This eggshell provides protection against environmental disturbances and allows for the exchange of gases [20]. After fertilization this layer undergoes a hardening process for the prevention of polyspermy. The zona radiata comprises two groups of subunits, ZI-1, 2 and ZI-3. The precursors of these proteins have been identified as choriogenin H (high molecular weight) and choriogenin L (low molecular weight), respectively [19, 20]. These precursors are produced in the liver in normal response to estrogen and released into the bloodstream to be incorporated into the zona radiata in sexually mature females [19], fig. 4. This process is referred to as zonagenesis. Estrogen also stimulates the production of vitellogenin (Vtg) in the liver for the process of vitellogenesis, the production of egg yolk proteins [19]. Vitellogenin is released by the liver into the bloodstream to be taken up by maturing oocytes, cleaved into the yolk proteins lipovitellin and phovitin and stored as a food reserve for the developing embryo [21].

. The up regulation of the vitellogenin gene found in this study is consistent with that observed in a study on zebrafish [22] where sensitivity of $17 \beta$-estradiol and $17 \alpha$-ethinylestradial to induce vitellogenesis was measured via ELISA assay. The exposure to estrogen or estrogen-like 
compounds has been found to increase the number of estrogen receptors, as well as increase vitellogenesis in the liver [23]. High levels of Vtg are normally found in females actively undergoing oogenesis. In males, the gene for Vtg is usually suppressed; however, this study and others have shown that the exposure to estrogen induces the production of Vtg in males and could account for the increase of individuals with intersex gender in fish populations found downstream of sewage treatment facilities.

Novel genes identified by this study include three heat shock proteins, hsp70, hsp90, and hsp8. Heat shock proteins are a group of proteins that are present in all cells in all organisms [24]. They become active when a cell undergoes various types of environmental stresses like extreme temperatures or oxygen deprivation. Heat shock proteins are also present in cells under perfectly normal conditions, acting like 'chaperones,' making sure that the cell's proteins are in the right conformation and in the right place at the right time. Hsp90 has been identified as playing a role in oogenic protein synthesis [20]. It is associated with estrogen receptors in the liver and aids the receptors in binding estrogen prior to translocation into the nucleus. The exposure to higher levels of estrogen may elicit the production of more hsp90 proteins to aid in the cellular uptake of estrogen.

Hsp70's role in this process is less clear. This protein may assist in general protein folding, as well as important cellular processes such as transport of proteins across membranes and the regulation of the heat shock response [25]. Hsp70 may also be involved in the process of protein translation. This function may explain its estrogenic induction at a time when oogenic protein production is being increased due to estrogen exposure.

Ubiquitin, another heat shock protein, is sometimes referred to as hsp 8 because it has a relative molecular weight of $8500 \mathrm{Da}$ [26]. Ubiquitin is a protein that plays an important role in 
regulating the intracellular degradation of cytoplasmic proteins [26]. Hsp8 may function in binding and marking proteins for uptake and breakdown by proteosomes. With increased protein production, it may be possible that there are more errors being made during the process. This may increase the necessity of a protein such as hsp8 to assist in the disposal of nonfunctional protein products. Errors made during oogenic protein synthesis may also lead to small changes made in the zona radiata proteins produced that could cause the thickness and decrease in strength of the eggshell, thus reducing the ability to provide protection during early embryonic development and the prevention of polyspermy [21]. This may account for the reduced reproductive success seen in wildlife exposed to estrogen in environments affected by effluents released from sewage treatment facilities [7, 8, and 9].

Choriogenin Hminor was also tentatively identified by this study as being estrogeninduced. Most choriogenin studies have focused on choriogenin $\mathrm{H}$ and choriogenin $\mathrm{L}$.

Sugiyama, et al. [27] consider choriogenin Hminor to be the third major subunit of the inner layer of the egg envelope of medaka. As such, the induced up regulation of this protein demonstrated by this study correlates with the commonly found up regulation of choriogenins $\mathrm{H}$ and $\mathrm{L}$ by other studies [17, 18, and 19].

\section{Goitrogen (T3)}

Excessive exposure to goitrogens such as T3 has been found to be toxic and cause severe developmental defects during early embryonic development [28]. It has been proposed that the embryonic to larval transitory phase in many teleost species may be dependent on the timing and level of thyroid hormones. Thyroid hormones are involved in regulating metabolism [29]. This may be a possible explanation for the reduced egg hatchings seen in fish where such compounds are found. Exposure to T3 in this study resulted in the up regulation of the gene, glutathione S- 
transferase. Glutathione S-transferase is a family of enzymes that use glutathione in various reactions involved in transforming compounds such as carcinogens, therapeutic drugs, and products of oxidative stress [30]. The up regulation of this gene may stem from the need to detoxify the body of this endocrine disruptor. Exposure to T3 also resulted in the up regulation of the GABA receptor protein. The GABA receptor is a superfamily of ligand-gated channels [31]. These receptors are involved in the inhibition of presynaptic inhibition in the central nervous system [32]. It is unclear exactly how the up regulation of this gene relates to the reproductive problems seen in some wildlife. Thyroid hormones can interact with receptors to affect the synthesis of specific proteins during development and alter brain function [33]. They can also interact with sex hormones in such a way that low levels of thyroid hormones can prolong the critical period for testosterone-induced masculinization whereas, high levels can reduce the sensitivity to testosterone [33]. The exposure to T3 may affect other steroids in the body, thus indirectly affecting the regulation of GABA receptor function.

\section{Flutamide}

Flutamide is a known endocrine disruptor used as a hormonal therapy for treating prostate cancer [35]. Because flutamide has a structure similar to testosterone, it can attach to the receptors on the surface of the prostate cancer cells to block and prevent the attachment of testosterone. Without a regular supply of testosterone, the cancer growth is reduced or stopped altogether [35]. Exposure to flutamide resulted in the up regulated expression of choriogenin L, choriogenin Hminor, and zona radiata-2. These genes are normally expressed in females actively undergoing oogenesis. The exposure to this antiandrogen may actively induce the process of oogenesis in females. In which case, one would expect to see these genes being expressed. It would be interesting to see the effects of gene expression on male medaka. 
Previous studies have resulted in the induced expression of choriogenins [19] and zona radiata [20] in male fish in response to estrogenic compounds. Similar effects may be seen in the presence of an antiandrogen such as flutamide where testosterone may not be able to function in its normal capacity during male sexual differentiation. In rats and humans, androgen production during fetal development is required for normal male sexual differentiation and proper development of the testes [36]. It may be possible that in the absence of the effects of testosterone, these genes associated with female oogenesis will be expressed. This might account for the higher number of females found in fish populations and reduced testicular development and fertility where antiandrogenic endocrine disrupting chemicals are found in the environment [10].

It is clear that the exposure to endocrine disrupting chemicals such as estradiol-17 $\beta$, goitrogen (T3), and flutamide can have tremendous effects on the endocrine system of an organism. Comparison of the ESTs between the treatments reveals that more than one endrocrine disruptor can affect a particular gene. Expression of the same 25 ESTs was induced by all treatment, table 2. Other ESTs were induced by 2 of the 3 treatments, while others were found to be unique to the specific treatment. This information can provide for further study and investigation into the complicated biological pathways and interactions involved with the exposure to such chemicals. This study only focuses on the genes that were up regulated by the exposure to these endocrine disruptors. It would be interesting to get a profile of the genes that are down regulated.

Further studies on vertebrates such as medaka can clarify the effects of such compounds on gene expression patterns and possible hazards of such compounds in the environment. Microarray analysis has provided patterns of gene expression for numerous genes simultaneously 
affected by the exposure to endocrine disrupting chemicals. This method provides a clear and more accurate picture of the complex function of genes in a living organism and their responses to environmental exposure to such chemicals. The genes identified in this study may serve as biomarkers which can act as the first measurement in an approach to signal the effects caused by the presence of endocrine disruptors [19]. Measuring the levels of these biomarkers may provide a screening mechanism for the presence of endocrine disrupting chemicals in the environment. Further development of microarray technology may provide a means to screen for multiple biomarkers simultaneously and provide a more rapid and accurate tool for assessing endocrine disruption due to environmental pollutants. 

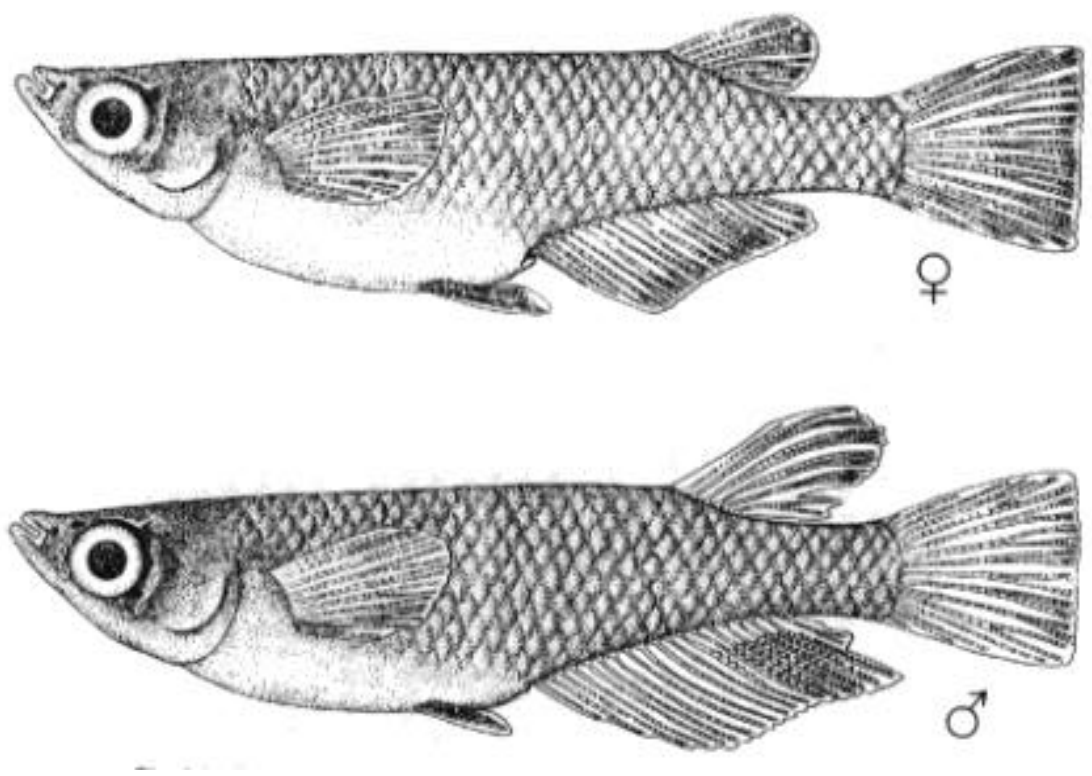

Figure 1. Female and male of the medaka, Oryzias latipes. Drawn by Yamamoto, 1969 [4]. 


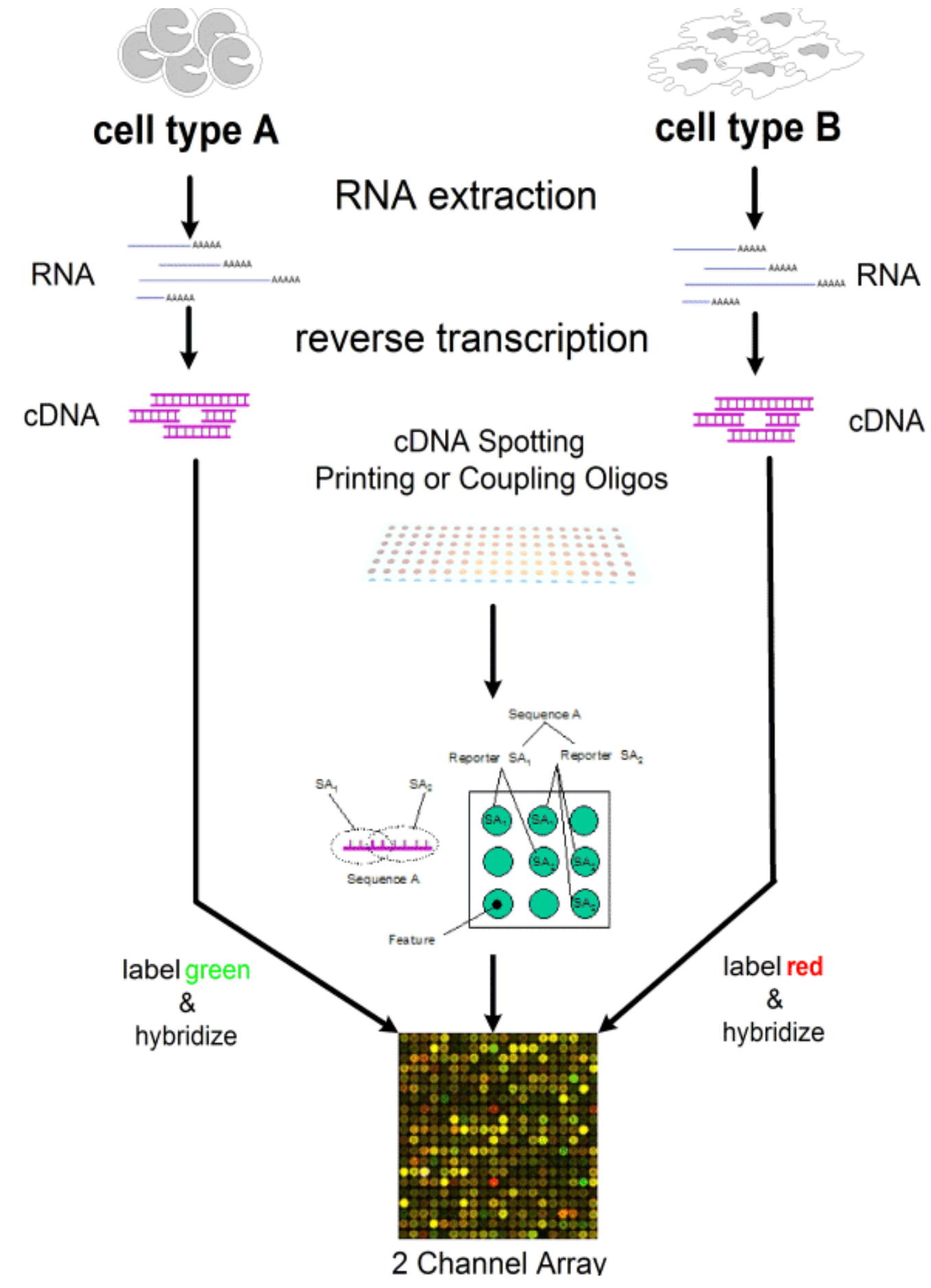

Figure 2. Diagram of experimental procedure using 2-channel microarray. (http://tigpbp.iis.sinica.edu.tw/05_Spring/access\%20to\%20all/20050324Hwang.ppt\#13) 



Figure 3. Immunohistochemical staining of a cod (Gadus morhua) ovarian follicle with oocyte, probed with rabbit antiserum to cod zona radiata proteins. (A) Section of whole oocyte, demonstrating specific immunohistochemical staining of the zona radiata, with no cross-reaction to yolk material (Y). (B) Higher magnification of the cod follicle. Zr denotes the zona radiata (positively stained). The follicle cells (theca, T, and granulosa, G) are indicated with arrowheads. Spherical bodies represent unstained yolk granules [20]. 


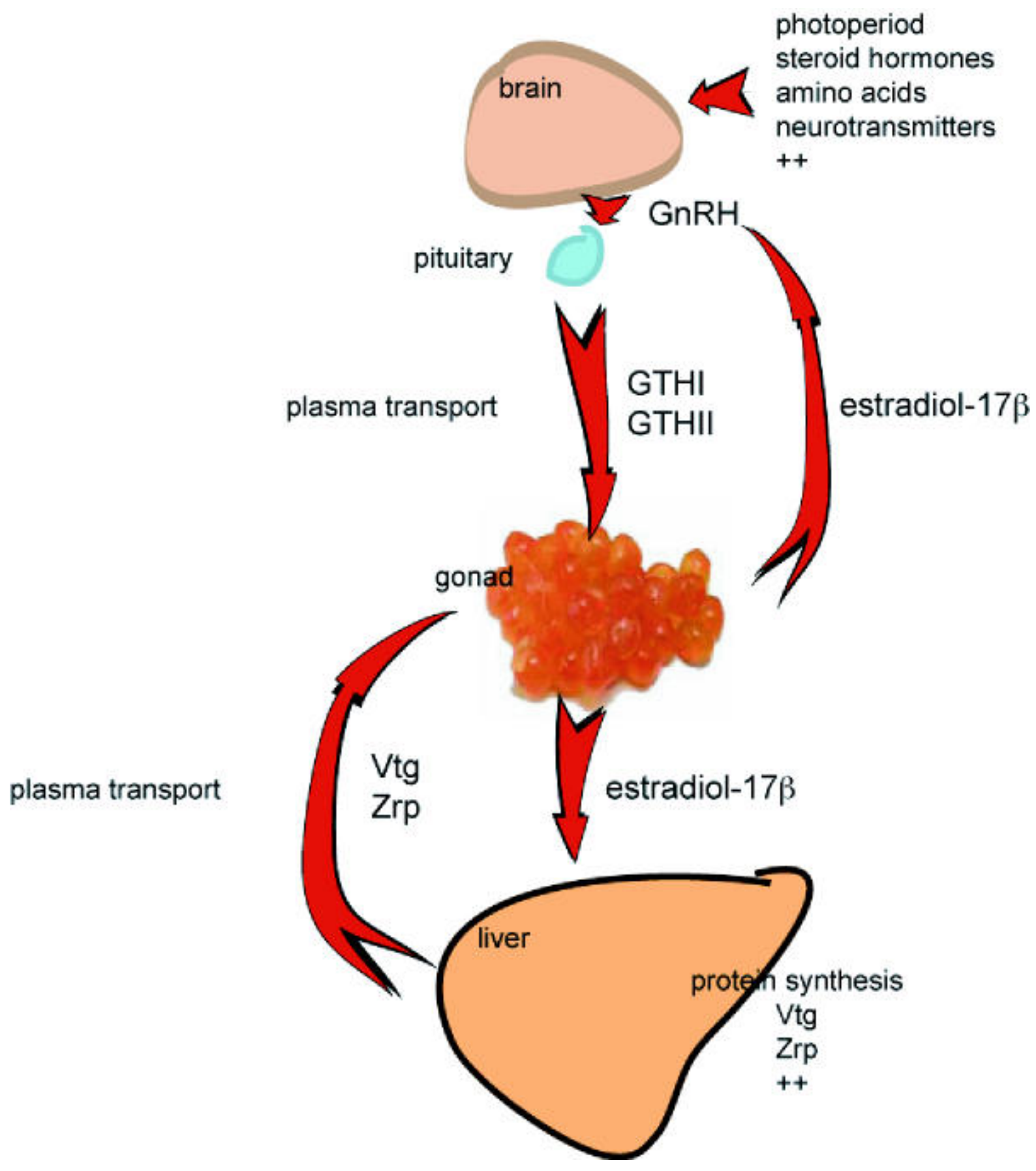

Figure 4. Schematic representation of the hypothalamus-pituitary-gonadal-liver (HPGL) axis during oogenic protein synthesis in female teleosts. The HPGL is regulated through the negative feedback mechanism by estradiol-17 $\beta$. The hypothamalus, pituitary, gonad and liver are all potential targets for endocrine disruptors, as discussed in the text. $\mathrm{GtH}=$ gonadotropin I \& II $[20]$. 


\section{Table 1. Genes tentatively identified in the study as being up regulated.}

\begin{tabular}{|c|c|c|}
\hline Estradiol-17 $\beta$ Treatment & T3 Treatment & Flutamide Treatment \\
\hline $\begin{array}{l}\text { - Choriogenein L } \\
\text { - Choriogenin Hminor } \\
\text { - Choriogenin H } \\
\text { - Zona radiata-2 } \\
\text { - Zona radiata structural protein } \\
\text { - VgC-phosvitinless vitellogenin } \\
\text { - Mitochondrial cytb gene for } \\
\text { cytochrome b } \\
\text { - Heat shock protein } 70 \text { cognate } \\
\text { - Heat shock protein } 8 \\
\text { - Heat shock protein } 90 \\
\text { - Heat shock protein } 90 \text { beta } \\
\text { - Polypeptide elongation factor } 1 \\
\text { alpha } \\
\text { - Transferrin }\end{array}$ & $\begin{array}{l}\text { - Glutathione S-transferase } \\
\text { - GABA receptor protein }\end{array}$ & $\begin{array}{l}\text { - Choriogenin L gene } \\
\text { - Choriogenin Hminor } \\
\text { - Zona radiata-2 }\end{array}$ \\
\hline
\end{tabular}




\begin{tabular}{|c|c|}
\hline Treatment & Number of ESTs expressed \\
\hline $\begin{array}{l}\text { Estradiol-17 } \beta \text {, goitrogen (T3), and } \\
\text { flutamide }\end{array}$ & 25 \\
\hline Estradiol-17 $\beta$ and flutamide only & 60 \\
\hline Estradiol-17 $\beta$ and goitrogen (T3) only & 13 \\
\hline Goitrogen (T3), and flutamide only & 30 \\
\hline Estradiol- $17 \beta$ only & 125 \\
\hline Goitrogen (T3) only & 56 \\
\hline Flutamide only & 652 \\
\hline
\end{tabular}




\section{Acknowledgements}

I am grateful to the Biosciences Directorate of the Lawrence Livermore National

Laboratory, for their willingness to participate in the Edward Teller Education Center:

Biotechnology Research Academy, Level IV Internship. I would like to thank Anu Chakicherla

for taking me under her wing and sharing with me her technical expertise in the use of BLAST

program and the NCBI database. I will be able to take my experience with actual research in biotechnology back to the classroom to share with my students and demonstrate the application of the topics they study. I hope to encourage them to develop their research skills in their pursuit of a science related career. 


\section{References}

[1] Ministry of the Environment, Japan and Chemicals Evaluation and Research Institute, Japan. "Chapter 1: Suitability of Medaka Fish as a Test Organism and New Medaka Strains." In: Medaka, Oryzias latipes. Development of Test Methods and Suitability of Medaka as Test Organism for Detection of Endocrine Disrupting Chemicals, p. 7, Feb. 2003.

[2] Wittbrodt, J., A. Shima, and M. Schartl. "Medaka-A Model Organism from the Far East." Nature Reviews, 3:53-64, Jan. 2002.

[3] Ishikawa, Y. "Medakafish as a model system for vertebrate developmental genetics." Bioessays, 22:487-495, 2000.

[4] Yamamoto, T. (1975) "Intoductory Remarks on the Medaka" in Medaka, Biology and Strains (T. Yamamoto, ed.), Yugakusya Publ. [Online]. pp. 1-16. Available: http://bioll.bio.nagoya-u.ac.jp:8000/remarks.html

[5] Canadian Centre for Occupational Health \& Safety. (2000, Feb.). OSH Answers: Endocrine Disruptors. [Online]. Available: http://www.ccohs.ca/oshanswers/chemicals/endocrine.html

[6] Colborn, T., F.S. vom Saal, and A.M. Soto. "Developmental Effects of Endocrine-Disrupting Chemicals in Wildlife and Humans." Environ Health Perspect 101: 378-384, 1993.

[7] Shioda, T. and M. Wakabayashi. "Effect of certain chemicals on the reproduction of medaka (Oryzias latipes)." Chemoshere 40:239-243, 2000.

[8] Pickering, A.D. and J.P. Sumpter. "Comprehending Endocrine Disruptors in Aquatic Environments." Evironmental Science \& Technology, 331A-336A, Sept. 2003.

[9] Metcalf, C.D., T.1. Metcalf, Y. Kiparussus, B.G. Koenig, R.J. Hughes, T.R. Croley, R.E. March, and T. Potter. "Estrogenic potency of chemicals detected in sewage treatment plant effluents as determined by in vivo assays with Japanese medaka (Oryzias latipes)." Environ Toxicol Chem. 2:297-308, Feb. 2001.

[10] Jobling, S., D. Casey, T. Rodgers-Gray, J. Oehlmann, U. Schulte-Oehlmann, S. Pawlowski, T. Baunbeck, A.P. Turner, and C.R. Tyler. "Comparative responses of mollusks and fish to environmental estrogens and an estrogenic effluent." Aquatic Toxicology, 65:205-220, 2003.

[11] Shi, Leming. (2002, Jan.). DNA Microarray (Genome Chip)-Monitoring the Genome on a Chip. [Online]. Available: http://www.gene-chips.com

[12]Carlsen, E., A.Giwercman, N. Keiding, and N.E. Skakkebaek. "Evidence for the decreasing quality of semen during the past 50 years." BR Med J. 305:609-612, 1992.

[13] Sharpe, R.N., and N.E. Skakkebaek. "Are oestrogens involved in failing sperm counts and disorders of the male reproductive tract?" Lancet 341:1392-1395, 1993. 
[14] Sugnet, Charles. (1999, Nov.). Microarray FAQ. [Online]. Available: http://www.soe.ucsc.edu/ sugnet/microarray/microarray_FAQ.html\#cohybridizations

[15] Altschul, S.F., T.L. Madden, A.A. Schaffer, J. Zhang, Z. Zhang, W. Miller, and D.J. Lipman. "Gapped BLAST and PSI-BLAST: a new generation of protein database search programs.” Nucleic Acids Res. 25(17):3389-402, Sept. 1997.

[16] Nakamura, H., K.Kawano, O. Yoshikawa, T. Takeda,Y. Kagami, and T. Kusano. (2003). "cDNA Microarray Analysis of Japanese Medaka (Oryzias latipes) Exposed to 17ß-estradiol, Nonylphenol and Bisphenol-A.” Ecogenomics, Inc. Kurume, Fukuoka, Japan. [Online]. Available: http://www.ecogenomics.co.jp/ecogenomics_file.2.pdf

[17] Murata, K., K. Yamamoto, I. Iuchi, I. Yasumasu, and K. Yamagami. "Intrahepatic expression of genes encoding choriogenins: precursor proteins of the egg envelope of fish, the medaka, Oryzias latipes.” Fish Physiology and Biochemistry 17:135-142, 1997.

[18] Ueno, T., S. Yasumasu, S. Hayashi, and I. Iuchi. "Identification of choriogenin cisregulatory elements and production of estrogen-inducible, liver-specific transgenic Medaka." Mechanisms of Development 121(7-8):803-815, July 2004.

[19] Lee, C., J.G. Na, K. Lee, and K. Park. "Choriogenin mRNA induction in make medaka, Oryzias latipes as a biomarker of endocrine disruption." Aquatic Toxicology 61:233-241, 2002.

[20] Arukwe, A. and A. Goksøyr. "Eggshell and egg yolk proteins in fish: hepatic ptoeins for the next generation: oogenetic, population, and evolutionary implications of endocrine disruption." Comparative Hepatology 2:4, 2003.

[21] Arukwe, A., F.R. Knudsen, and A. Goksøyr. "Fish Zona Radiata (Eggshell) Protein: A Sensitive Biomarker for Environmental Estrogens." Environmental Health Perspectives 105 (4): 418-422, 1997.

[22] Rose, J., H. Holbech, C. Lindholst, U. Norum, A. Povlsen, B. Korsgaard, and P. Bjerregaard. "Vitellogenin induction by $17 \beta$-estradiol and $17 \alpha$-ethinylestradiol in male zebrafish (Danio rerio)." Comparative Biochemistry and Physiology Part C 131:531-539, 2002 .

[23] Larkin, P. I. Knoebl, and N.D. Denslow. "Differential gene expression analysis in fish exposed to endocrine disrupting compounds." Comparative Biochemistry and Physiology Part B 136: 149-161, 2003.

[24] Antigenics. (2005). "Heat shock proteins: basics." [Online]. Available: http://www.antigenics.com/products/tech/hsp/ 
[25] Wegele, H., L. Müller, and J. Buchner. "Hsp70 and Hsp90 - a relay team for protein folding.” Rev Physiol Biochem Pharmacol 151:1-44, 2004.

[26] Rácz, Attila. (2000). "Ubiquitin, (and the family of hsp8)." In: The kinetics of protein folding. [Online]. http://www.chaperone.sote.hu/mainindex.html

[27] Sugiyama,H., S. Yasumasu, K. Murata, I. Iuchi, and K.Yamagami. "The third egg envelope subunit in fish: cDNA cloning and analysis, and gene expression." Dev. Growth Differ. 40 (1): $35-45,1998$.

[28] Liu Y.W. and W.K. Chan. "Thyroid hormones are important for embryonic to larval transitory phase in zebrafish." Differentiation 70(1): 36-45, 2002.

[29] Endocrine Web and the Norman Endocrine Surgery Clinic. (2005, Feb.). "How Your Thyroid Works: A delicate Feedback Mechanism." [Online]. Available:

http://www.endocrineweb.com/thyfunction.html

[30] MedicineNet. (2005). "Definition of Glutahione S-transferase.” [Online]. Available: http://www.medterms.com/script/main/art.asp?articlekey=31473

[31] Qian, Haohua. (2000). "GABAc Receptors in the Vertebrate Retina." [Online]. Available: http://webvision.med.utah.edu/GABA-C.htm\#Molecular\%20biology\%20of\%20GABAc\%20receptors

[32] King, M.W. (2004, Oct.) “GABA.” [Online]. Available:

http://web.indstate.edu/thcme/mwking/nerves.html\#gaba“"

[33] Siegel, G.J., B.W. Agranoff, S.K. Fisher, R.W. Albers, and M.D. Uhler. (1999).

Biochemistry of Thyroid Hormone Actions on Brain" in Basic Neurochemistry: Molecular, Cellular and Medical Aspects, $6^{\text {th }}$ ed. [Online]. Available:

http://www.ncbi.nlm.nih.gov/books/bv.fcgi?rid=bnchm.section.3527

[34] Siegel, G.J., B.W. Agranoff, S.K. Fisher, R.W. Albers, and M.D. Uhler. (1999). "GABA Receptor Physiology and Pharmacology" in Basic Neurochemistry: Molecular, Cellular and Medical Aspects, $6^{\text {th }}$ ed. [Online]. Available:

http://www.ncbi.nlm.nih.gov/books/bv.fcgi?rid=bnchm.section.1181

[35] CancerBACUP. (2005, Mar.). "Flutamide (Chimax ${ }^{\circledR}$, Drogenil@).” [Online]. Available: http://www.cancerbacup.org.uk/Treatments/Hormonaltherapies/Individualhormonaltherapies/ Flutamide

[36] McIntyre, B.S., N.J. Barlow, and P.M.D. Foster. "Androgen-Mediated Development in Male Rat Offspring Exposed to Flutamide in Utero: Permanence and Correlation of Early Postnatal Changes in Anogenital Distance and Nipple Retention with Malformations in Androgen-Dependent Tissues.” Toxicological Sciences 62: 236-249, 2001. 